\title{
Perfilhamento, acúmulo de forragem e composição bromatológica do capim-braquiária adubado com nitrogênio ${ }^{1}$
}

\author{
Luciano de Melo Moreira ${ }^{2 *}$, Janaina Azevedo Martuscello ${ }^{3}$, Dilermando Miranda da \\ Fonseca $^{4}$, Claudio Mistura ${ }^{5}$, Rodrigo Vieira de Morais ${ }^{6}$, José Ivo Ribeiro Júnior ${ }^{7}$
}

\footnotetext{
${ }^{1}$ Pesquisa financiada pela Fapemig.

2 Doutorando em Zootecnia - Departamento de Zootecnia, Universidade Federal de Viçosa.

3 Pós-doutoranda do Departamento de Zootecnia, Universidade Federal de Viçosa.

${ }^{4}$ Departamento de Zootecnia, Universidade Federal de Viçosa. Bolsista do CNPq.

${ }^{5}$ Departamento de Tecnologia e Ciências Sociais, Universidade Estadual da Bahia.

${ }^{6}$ Escola Agrotécnica Federal de Muzambinho.

${ }^{7}$ Departamento de Informática, Universidade Federal de Viçosa.
}

RESUMO - Avaliaram-se a demografia de perfilhos, a composição morfológica do pasto, o índice de área foliar (IAF), a taxa de acúmulo de massa seca de forragem (TAcMS) e os teores de proteína bruta, fibra em detergente neutro e lignina e os coeficientes de digestibilidade in vitro da massa seca de Brachiaria decumbens cv. Basilisk submetido a adubação nitrogenada (75, 150, 225 e 300 kg/ha.ano de N), em lotação contínua com taxa de lotação variável em dois anos agrícolas consecutivos. O delineamento foi em blocos casualizados, com duas repetições. No primeiro ano, a demografia de perfilhos vivos não foi alterada pelos meses de avaliação, mas, no segundo ano, foi maior nos meses de março e abril. A adubação nitrogenada promoveu resposta linear positiva na demografia de perfilhos vivos, no índice de área foliar e na taxa de acúmulo de massa seca. Maiores proporções de lâminas foliares foram constatadas em março do primeiro ano e em dezembro e janeiro do segundo ano, entretanto, as proporções de colmos no pasto não diferiram entre os meses de avaliação nos dois anos. Também foram observadas respostas lineares positivas dos teores de PB às doses de nitrogênio aplicadas em todos os meses nos dois anos. Os teores de FDN e lignina do capim-braquiária são influenciados pelos meses de avaliação e variam entre anos.

Palavras-chave: capim-braquiária, lotação contínua, nitrogênio

\section{Tillering, forage accumulation and bromatological composition of Brachiaria grass under nitrogen fertilization}

\begin{abstract}
The objective of this study was to evaluate tiller demography, pasture morphological composition, leaf area index, dry matter herbage accumulation, dry matter in vitro digestibility and crude protein, neutral detergent fiber (NDF) and lignin contents of Brachiaria decumbens cv. Basilisk (Signalgrass), under nitrogen fertilization (75, 150, 225, 300 kg/ha.year of $\mathrm{N}$ ) and continuous stock management with variable stocking rates, for two consecutive years. A randomized complete block design was used with two replications. In the first year, tiller demography did not differ, but in the second year it was increased in March and April. Nitrogen fertilization promoted a linear effect on tiller demography, leaf area index and dry matter accumulation. The percentage of leaf blades increased in March of the first year and in December/January of the second year, but stem percentage did not differ among the evaluated months in the two years. Positive linear response to the crude protein levels was observed as a result of applying nitrogen rates throughout the entire experiment. In both years, levels of NDF and lignin were not altered during the evaluation months.
\end{abstract}

Key Words: continuous stock management, nitrogen, signalgrass

\section{Introdução}

Na pecuária brasileira, as gramíneas do gênero Brachiaria são de reconhecida importância, pois ocupam 85\% das áreas de pastagens. A Brachiaria decumbens Stapf, exclusivamente, representa cerca de $55 \%$ desse total (Macedo, 2004). Apesar da importância econômica do gênero Brachiaria, constatam-se, com relativa frequência, falhas no sistema de produção de bovinos em pastagens, como consequência da não-adoção de estratégias e tecnologias geradas, além do restrito volume de informações disponíveis sobre princípios ecofisiológicos que possam

Este artigo foi recebido em 17/4/2008 e aprovado em 14/10/2008. 
nortear o manejo da pastagem para as gramíneas desse gênero, em especial a $B$. decumbens.

$\mathrm{O}$ nitrogênio $(\mathrm{N})$ é um dos principais nutrientes para manutenção da produtividade das gramíneas forrageiras ao longo dos anos, pois é constituinte essencial das proteínas e participa diretamente no processo fotossintético, por meio de sua composição na molécula de clorofila. Portanto, sua baixa disponibilidade para a forrageira acarreta redução na produção de forragem, iniciando o processo de degradação (Werner, 1994).

A adubação nitrogenada, em alguns casos, também pode influenciar a qualidade do pasto, principalmente pelo aumento do teor de proteína na forrageira (Moreira et al., 2003). De fato, o equilíbrio na relação energia:proteína da dieta favorece o consumo de forragem pelos animais, o que pode refletir em melhores ganhos individuais (Van Soest, 1994).

Esse estudo foi realizado com o objetivo de avaliar os efeitos da adubação nitrogenada e dos meses de avaliação (ou crescimento) sobre a demografia de perfilhos, o acúmulo de forragem e a composição bromatológica da Brachiaria decumbens cv. Basilisk sob lotação contínua.

\section{Material e Métodos}

O experimento foi realizado em pastagem de Brachiaria decumbens Stapf. cv. Basilisk (capim-braquiária) estabelecida em 1997. A área experimental pertence ao setor de Forragicultura do Departamento de Zootecnia da Universidade Federal de Viçosa, em Viçosa, Minas Gerais ( $20^{\circ} 45^{\prime}$ de latitude Sul, $42^{\circ} 51$ ' de longitude Oeste e $651 \mathrm{~m}$ de altitude). O clima, pelo sistema de Köppen (1948), é do tipo CWA, com estações seca (maio a outubro) e chuvosa (novembro a abril) bem definidas (Tabela 1).

O solo da área experimental, classificado como Latossolo Vermelho Amarelo de textura argilosa na camada de 0 a $20 \mathrm{~cm}$ de profundidade, apresentou as seguintes características químicas (média das unidades experimentais piquetes): $\mathrm{pH}$ em $\mathrm{H}_{2} \mathrm{O}$ - 5,2 (relação 1:2,5); P - 5,18 e K 148,75 mg/dm³ (Mehlich-1); Ca - 2,83, Mg - 0,82 e Al $0,13 \mathrm{cmol}_{\mathrm{c}} / \mathrm{dm}^{3}(\mathrm{KCl}-1 \mathrm{~mol} / \mathrm{L})$; soma de bases - 4,03 e CTC a pH 7 - 10,69 $\mathrm{cmol}_{\mathrm{C}} / \mathrm{dm}^{3}$; saturação por bases (V\%) - 37,65; saturação por alumínio (m\%) - 3,43; e matéria orgânica $4,24 \mathrm{dag} / \mathrm{kg}$.

Em virtude dos resultados de análise do solo, aplicou-se 0,7 t/ha de calcário dolomítico na superfície, em novembro de 2001, objetivando atingir 50\% da saturação por bases. Em dezembro de 2001 e novembro de 2002, foram aplicados em cobertura $100 \mathrm{~kg} / \mathrm{ha}$ de $\mathrm{P}_{2} \mathrm{O}_{5}$ na forma de superfosfato simples em toda área experimental e $45 \mathrm{~kg} / \mathrm{ha}$ de $\mathrm{K}_{2} \mathrm{O}$, em média, de forma que as unidades experimentais (piquetes) receberam doses de cloreto de potássio diferenciadas, suficientes para proporcionar disponibilidade de $150 \mathrm{mg} / \mathrm{dm}^{3}$ de $\mathrm{K}_{2} \mathrm{O}$ no solo.

O experimento foi desenvolvido em dois anos agrícolas consecutivos: dezembro de 2001 a abril de 2002 e novembro de 2002 a abril de 2003. Os tratamentos consistiram de quatro doses de nitrogênio (N) (75, 150, 225 e 300 kg/ha.ano), parceladas em três aplicações sob a forma de ureia e em três períodos de avaliação no primeiro ano (1 - 31/1/2002 a 15/2/2002; 2 - 8/3/2002 a 23/3/2002; e 3 - 12/4/2002 a

Tabela 1 - Precipitação total e valores médios de insolação, umidade relativa do ar e temperatura (mínima, máxima e média) durante dois períodos experimentais

\begin{tabular}{|c|c|c|c|c|c|c|c|}
\hline \multirow{2}{*}{$\begin{array}{l}\text { Período } \\
\text { Mês/ano }\end{array}$} & \multirow{2}{*}{ Total (mm) } & \multirow{2}{*}{$\begin{array}{l}\text { Precipitação pluvial } \\
\text { (horas/dia) }\end{array}$} & \multirow{2}{*}{$\begin{array}{l}\text { Insolação } \\
\text { relativa (\%) }\end{array}$} & \multirow[t]{2}{*}{ Umidade } & \multicolumn{3}{|c|}{$\begin{array}{c}\text { Temperatura }\left({ }^{\circ} \mathrm{C}\right) \\
\text { experimental }\end{array}$} \\
\hline & & & & & Mínima & Máxima & Média \\
\hline \multirow[t]{5}{*}{ Primeiro ano } & Nov/01 & 231,50 & 4,94 & 81,73 & 18,68 & 27,70 & 22,18 \\
\hline & Dez/01 & 218,30 & 4,55 & 80,56 & 18,75 & 27,09 & 22,02 \\
\hline & $\mathrm{Jan} / 02$ & 270,10 & 5,23 & 81,32 & 19,03 & 28,40 & 22,69 \\
\hline & *Mar/02 & 98,50 & 8,52 & 78,32 & 18,29 & 29,63 & 22,57 \\
\hline & *Abr/02 & 1,80 & 9,11 & 74,07 & 17,10 & 30,84 & 22,33 \\
\hline \multirow[t]{3}{*}{ Segundo ano } & Nov/02 & 218,20 & 5,55 & 78,75 & 18,14 & 27,82 & 21,86 \\
\hline & *Dez/02 & 279,10 & 4,67 & 82,19 & 19,66 & 28,55 & 23,07 \\
\hline & $\mathrm{Jan} / 03$ & 432,70 & 3,51 & 84,10 & 20,15 & 28,36 & 23,00 \\
\hline
\end{tabular}

Fonte: Estação Meteorológica do Departamento de Engenharia Agrícola da UFV.

* Adubação nitrogenada (primeiro ano: $1 / 3$ da dose em cada aplicação - 23/1/2003; 27/2/2003; 30/3/2003 - segundo ano: 1/3 da dose em cada aplicação - 1/12/2002; 1/2/2003; 4/3/2003) 
27/4/2002) e em cinco períodos de avaliação no segundo ano ( 1 - 5/12/2002 a 20/12/2002; 2 - 9/1/2003 a 24/1/2003; 3 - 6/2/2003 a 21/2/2003; 4 - 13 a 28/3/2003; e 5 - 10/4/2003 a 25/4/2003). O delineamento experimental foi em blocos casualizados, com duas repetições (oito piquetes com áreas de 0,25 a 0,4 ha), arranjados em esquema de parcelas subdivididas, de modo que nas parcelas foram avaliadas as doses de nitrogênio e nas subparcelas os períodos (medidas repetidas no tempo).

A área experimental foi submetida a pastejo intenso, para rebaixamento do pasto e a roçada a $10 \mathrm{~cm}$ do nível do solo para padronização da altura. Após a rebrotação, manteve-se a altura média em torno de $20 \mathrm{~cm}$ em todos os piquetes.

O controle da altura foi realizado por meio de ajustes na taxa de lotação animal, de modo a promover condições de pressão de pastejo idênticas em todos os níveis de nitrogênio, utilizando-se o método put and take. Para isso, foram utilizados dois grupos distintos (animais-teste e animais pastejadores de novilhos mestiços Holandês $\times$ Zebu, nãocastrados e com peso médio inicial de $238 \mathrm{~kg}$. Assim, os novilhos foram colocados ou retirados dos piquetes quando a altura média do pasto oscilava em $20 \pm 2 \mathrm{~cm}$. O sistema de pastejo em lotação contínua adotado teve taxa de lotação variável e os novilhos de equilíbrio, quando retirados dos piquetes, foram mantidos em pastagem de 2,5 ha de capimbraquiária contígua ao experimento. A altura do pasto foi monitorada duas vezes por semana, por meio de 50 leituras aleatórias realizadas em cada piquete, utilizando-se régua graduada com divisões de $1 \mathrm{~cm}$.

As avaliações foram iniciadas em janeiro de 2002 e dezembro de 2003, quando houve estabilização do controle da altura do pasto em todos os piquetes, e foram encerradas em 30 de abril de 2002 e de 2003.

A partir da coleta de três amostras de forragem por piquete em locais com altura média momentânea, a cada mês, foram avaliados o número de perfilhos (quadrado de amostragem de $25 \times 25 \mathrm{~cm}$ ), a composição morfológica e o índice de área foliar - IAF (quadrado de amostragem de $40 \times 40 \mathrm{~cm}$ ). Os perfilhos basilares, em laboratório, foram discriminados em vivos (vegetativos e reprodutivos somados) e mortos. A estimativa do número de perfilhos por $\mathrm{m}^{2}$ de cada amostra foi obtida multiplicando-se o número de perfilhos presentes no quadrado de área conhecida $\left(0,0625 \mathrm{~m}^{2}\right)$ por 16 . A média dos valores das três amostras representaram a média geral por piquete.

Para avaliação da composição morfológica (lâminas foliares, colmos e material morto) e do índice de área foliar, as amostras foram pesadas e, posteriormente, subamostradas e fracionadas em lâminas foliares, colmos (colmos + bainhas foliares) e material morto (colmos e folhas mortas). Após separação desses componentes, a área foliar de uma subamostra de lâminas foliares verdes foi mensurada utilizando-se o sistema medidor de área. Posteriormente, essas lâminas foliares foram levadas para secagem em estufa a $65^{\circ} \mathrm{C}$, onde permaneceram até atingir peso constante, juntamente com os demais componentes da planta (colmos e material morto).

Por meio das relações obtidas entre a matéria seca (MS) e a área de lâminas foliares verdes, estimaram-se a área total de lâminas foliares verdes na área de solo amostrada $\left(0,16 \mathrm{~m}^{2}\right)$ e o índice de área foliar correspondente (área de lâminas foliares/área de solo). O índice de área foliar médio para cada piquete foi calculado a partir das três amostras de matéria seca de forragem. A relação lâmina foliar:colmo foi obtida pela divisão dos valores médios de porcentagem de lâmina foliar pelos valores médios de porcentagem de colmo de cada piquete.

A taxa de acúmulo de matéria seca (TAcMS) de forragem ( $\mathrm{kg} / \mathrm{ha}$.dia de MS) foi calculada utilizando-se o método da diferença entre duas amostras pareadas (Klingman et al., 1943; Campbell, 1966a). O método baseia-se na utilização de gaiolas teladas $(1,5 \times 1,5 \times 1,0 \mathrm{~m})$, de modo a promover exclusão do pastejo e permitir estimativas de acúmulo de forragem. De cada grupo de dois locais pareados, sorteou-se um para corte imediato da forragem e outro para corte da forragem após 15 dias de sua demarcação (Campbell, 1966a), que ficou, portanto, excluído do pastejo pela gaiola telada. Em todos os locais, as amostras de forragem foram colhidas na superfície do solo, utilizando-se um quadrado de amostragem de $40 \times 40 \mathrm{~cm}$. Imediatamente após as colheitas do $1^{\mathrm{o}}$ e do $15^{\mathrm{o}} \mathrm{dia}$, as amostras de forragem foram pesadas, subamostradas e submetidas à secagem em estufa com ventilação forçada a $65^{\circ} \mathrm{C}$, durante 72 horas, para estimativa do teor de MS da forragem e das produções de matéria seca da forragem sujeita ao pastejo e daquela excluída do pastejo. A taxa de acúmulo de forragem, em $\mathrm{kg} / \mathrm{ha}$ ao dia de MS, foi calculada durante o intervalo de amostragem, conforme metodologia descrita por Campbell (1966a,b).

Foram calculados os teores de proteína bruta (PB) (AOAC, 1984, conforme descrito por Silva \& Queiroz, 2002), fibra em detergente neutro (FDN) e lignina (Van Soest, 1965; Silva \& Queiroz, 2002) e a digestibilidade in vitro da matéria seca (DIVMS), pelo método de Tilley \&Terry (1963).

Para as doses de nitrogênio, foram realizadas análises de regressão com seleção de modelos lineares e quadráticos significativos até $10 \%$ de probabilidade pelo teste t. Para os períodos de avaliação (meses), foi aplicado às médias o teste de Tukey a $5 \%$ de probabilidade e, para verificar a 
significância da interação entre os dois fatores, o teste $\mathrm{F}$ a $5 \%$ de probabilidade.

\section{Resultados e Discussão}

As médias da altura das plantas e seus respectivos desvios foram de 20,0 \pm 9,4 cm e 20,4 \pm 7,0 cm, no primeiro e segundo anos, respectivamente (Tabela 2). Em todas as doses de nitrogênio, as médias das alturas situaram-se entre 19,5 cm (primeiro ano) e 20,8 cm (segundo ano), portanto, próximo à altura desejada de $20 \mathrm{~cm}$. Entretanto, para os meses de avaliação, verificaram-se diferenças nas alturas, de 1,2 e 3,2 cm para janeiro do primeiro e do segundo ano, respectivamente, as quais estiveram acima de $20 \mathrm{~cm}$. Uma das explicações para que isso tenha ocorrido pode ser o fato de que esses meses coincidiram com o início das avaliações e nessa fase o manejo do pastejo estava sendo ajustado.

Cavalcante (2001), estudando pastagem de capimbraquiária em quatro alturas desejadas (10, 15, 20 e $25 \mathrm{~cm})$, obtiveram médias de 11,5; 12,7; 18,5 e 21,6 cm. De fato, conforme verificaram Gomide et al. (2002), o manejo do pastejo visando ao controle da altura do pasto não é simples, pois outras variáveis não controladas pelo manejador, como limitações dos fatores de ambiente, e o pastejo desuniforme, podem influenciar a altura. O pastejo desuniforme tornou-se evidente neste estudo pelos elevados desvios-padrão calculados para as médias de alturas do pasto (Tabela 2).

Não houve interação entre as doses de nitrogênio e os meses de avaliação para perfilhamento e acúmulo de forragem. Portanto, estudaram-se os efeitos de nitrogênio e de mês de avaliação separadamente.

A demografia de perfilhos vivos e mortos foi influenciada pelos meses de avaliação, com exceção da população de perfilhos vivos avaliada no primeiro ano (Tabela 3), o que pode ser explicado pelo manejo do pastejo, que foi ajustado com antecedência (janeiro) e pelas alturas do pasto (Tabela 2) que resultaram em intensidades de pastejo similares, não influenciaram a demografia de perfilhos vivos. Além disso, as avaliações foram precedidas de adubação (Tabela 1), o que provavelmente estimulou o perfilhamento.

Por outro lado, a população de perfilhos vivos foi alterada no segundo ano, com os maiores valores para os meses de março e abril, que diferiram apenas do valor do mês de dezembro, mas não podem ser considerados superiores àqueles referentes aos meses de janeiro e fevereiro. Os valores superiores para março e inferiores para dezembro devem-se, provavelmente, às intensidades de pastejo impostas, representadas pelas alturas do pasto, de $18 \mathrm{~cm} \mathrm{e}$ 23,2 cm, respectivamente (Tabela 2). Nesse sentido,

Tabela 2 - Alturas (cm) do pasto de Brachiaria decumbens cv. Basilisk adubado com diferentes doses de nitrogênio e avaliado em dois anos consecutivos

\begin{tabular}{|c|c|c|c|c|c|}
\hline \multirow[t]{2}{*}{ Quinzena/mês/ano } & \multicolumn{4}{|c|}{ Dose de nitrogênio (kg/ha) } & \multirow[t]{2}{*}{ Médias mensais } \\
\hline & 75 & 150 & 225 & 300 & \\
\hline \multicolumn{6}{|c|}{ Primeiro ano } \\
\hline 1a janeiro 2002 & $20,4 \pm 10,3$ & $22,7 \pm 10,0$ & $21,6 \pm 11,8$ & $25,7 \pm 13,1$ & $21,2 \pm 10,6$ \\
\hline *2a janeiro 2002 & $20,4 \pm 9,9$ & $20,1 \pm 10,1$ & $19,0 \pm 10,2$ & $19,4 \pm 9,8$ & \\
\hline $1^{\underline{a}}$ fevereiro 2002 & $19,4 \pm 8,4$ & $18,6 \pm 8,3$ & $19,6 \pm 9,6$ & $18,5 \pm 9,0$ & $19,2 \pm 8,8$ \\
\hline *2a fevereiro 2002 & $18,9 \pm 8,7$ & $20,1 \pm 8,1$ & $18,8 \pm 9,0$ & $20,1 \pm 9,1$ & \\
\hline 1a março 2002 & $20,7 \pm 10,2$ & $21,0 \pm 10,0$ & $20,4 \pm 10,4$ & $20,8 \pm 11,7$ & $20,2 \pm 10,2$ \\
\hline *2a março 2002 & $19,4 \pm 9,8$ & $19,4 \pm 8,9$ & $20,1 \pm 9,4$ & $20,2 \pm 10,9$ & \\
\hline 1a abril 2002 & $19,0 \pm 8,2$ & $20,8 \pm 8,1$ & $20,7 \pm 10,0$ & $20,4 \pm 9,3$ & $19,5 \pm 8,2$ \\
\hline $2^{\mathrm{a}}$ abril 2002 & $18,6 \pm 7,4$ & $19,3 \pm 7,0$ & $18,8 \pm 7,6$ & $18,3 \pm 7,8$ & \\
\hline Médias & $19,6 \pm 9,1$ & $20,2 \pm 8,8$ & $19,9 \pm 9,7$ & $20,4 \pm 10,1$ & $20,0 \pm 9,4$ \\
\hline \multicolumn{6}{|c|}{ Segundo ano } \\
\hline *1a dezembro 2002 & $20,9 \pm 8,1$ & $21,3 \pm 8,4$ & $25,6 \pm 10,9$ & $22,7 \pm 11,7$ & $23,2 \pm 9,6$ \\
\hline 2aㅡ dezembro 2002 & $20,9 \pm 8,8$ & $23,8 \pm 9,3$ & $24,7 \pm 9,8$ & $26,0 \pm 9,8$ & \\
\hline 1a janeiro 2003 & $20,7 \pm 9,4$ & $23,1 \pm 10,4$ & $23,0 \pm 7,7$ & $22,8 \pm 8,4$ & $21,4 \pm 7,9$ \\
\hline 2aa janeiro 2003 & $21,4 \pm 6,9$ & $21,7 \pm 7,2$ & $18,6 \pm 6,1$ & $19,7 \pm 7,2$ & \\
\hline *1 $1^{\mathrm{a}}$ fevereiro 2003 & $20,7 \pm 7,2$ & $20,2 \pm 5,8$ & $20,1 \pm 5,2$ & $20,8 \pm 6,3$ & $20,2 \pm 6,2$ \\
\hline $2^{a}$ fevereiro 2003 & $19,6 \pm 7,4$ & $20,3 \pm 6,1$ & $19,6 \pm 5,3$ & $20,2 \pm 6,4$ & \\
\hline *1 a março 2003 & $17,6 \pm 5,5$ & $19,0 \pm 5,8$ & $18,4 \pm 4,7$ & $18,2 \pm 6,1$ & $18,0 \pm 5,4$ \\
\hline 2ª março 2003 & $16,8 \pm 5,9$ & $18,5 \pm 5,2$ & $17,3 \pm 4,1$ & $18,1 \pm 6,1$ & \\
\hline 1a abril 2003 & $18,8 \pm 6,5$ & $22,1 \pm 6,2$ & $20,4 \pm 5,3$ & $21,4 \pm 8,2$ & $19,5 \pm 5,9$ \\
\hline $2^{\mathrm{a}}$ abril 2003 & $17,8 \pm 6,1$ & $19,1 \pm 5,3$ & $18,4 \pm 3,8$ & $18,1 \pm 5,8$ & \\
\hline Médias & $19,5 \pm 7,2$ & $20,9 \pm 7,0$ & $20,6 \pm 6,3$ & $20,8 \pm 7,6$ & $20,4 \pm 7,0$ \\
\hline
\end{tabular}

* Adubação nitrogenada (1/3 da dose - primeiro ano: 23/1/2003; 27/2/2003; 30/3/2003 - segundo ano: 1/12/2002; 1/2/2003; 4/3/2003). 
Tabela 3 - Demografia de perfilhos vivos e mortos em pastagem de Brachiaria decumbens adubada com nitrogênio e avaliada em dois anos consecutivos

\begin{tabular}{|c|c|c|c|c|c|}
\hline Característica & Dezembro & Janeiro & Fevereiro & Março & Abril \\
\hline \multicolumn{6}{|c|}{ Primeiro ano } \\
\hline Perfilhos vivos $/ \mathrm{m}^{2}$ & - & - & $2010 \mathrm{a}$ & $1689 a$ & $1844 a$ \\
\hline Perfilhos mortos $/ \mathrm{m}^{2}$ & - & - & $222 b$ & $325 b$ & $1140 \mathrm{a}$ \\
\hline \multicolumn{6}{|c|}{ Segundo ano } \\
\hline Perfilhos vivos/m² & $1924 b$ & $2188 \mathrm{ab}$ & $2434 \mathrm{ab}$ & $2629 a$ & $2550 a$ \\
\hline Perfilhos mortos $/ \mathrm{m}^{2}$ & $839 b$ & $785 b$ & $805 b$ & $1250 \mathrm{a}$ & $1462 \mathrm{a}$ \\
\hline
\end{tabular}

Médias na mesma linha seguidas da mesma letra não diferem (Tukey 5\%) entre si.

Sbrissia et al. (2001) discorreram sobre a lei de compensação tamanho/densidade, proposta por Matthew et al. (1995), a qual define que maior intensidade de pastejo (menor altura do pasto) reflete em maior número de perfilhos, porém mais leves, enquanto menor intensidade de pastejo gera menor número de perfilhos, porém mais pesados. Além disso, em março houve a aplicação da terceira dose de nitrogênio e as condições ambientais durante esse período estavam favoráveis (Tabela 1). Em dezembro e janeiro, no entanto, houve elevada precipitação (Tabela 1), o que pode ter promovido perdas de nitrogênio por lixiviação e, neste caso, o efeito do nutriente sobre o perfilhamento foi menos pronunciado.

A população de perfilhos mortos em abril foi superior à dos outros meses de avaliação no primeiro ano e em março e abril no segundo ano. Isso indica que, a partir de abril, a demografia de perfilhos vivos na pastagem pode cair, como consequência do maior número de perfilhos mortos e da estabilização do número de perfilhos vivos, conforme estudo realizdo por Morais et al. (2006), que verificaram redução na população de perfilhos vegetativos a partir de maio em pastagem de capim-braquiária.

Na avaliação da demografia de perfilhos, constatou-se efeito linear positivo das doses de nitrogênio no número de perfilhos vivos nos dois anos $(\hat{y}=1261,173+3,128 * N$; $\mathrm{R}^{2}=0,89$ e $\hat{\mathrm{y}}=1011,55+7,113^{* *} \mathrm{~N} ; \mathrm{R}^{2}=0,97$, respectivamente) e de perfilhos mortos no primeiro ano $(\hat{\mathrm{y}}=117,66+2,371 * \mathrm{~N}$; $\left.\mathrm{R}^{2}=0,95\right)$.

As equações de regressão para perfilhos vivos permitiram estimar população de 1.496 e 2.199 perfilhos $/ \mathrm{m}^{2}$ para o primeiro ano e de 1.545 e 3.145 perfilhos vivos $/ \mathrm{m}^{2}$ para o segundo ano, para as doses de 75 e $300 \mathrm{~kg} / \mathrm{ha}$ de $\mathrm{N}$, respectivamente. A população de perfilhos mortos aumentou significativamente de acordo com as doses de nitrogênio, apenas no primeiro ano. A equação ajustada permitiu estimar população de 295 e 829 perfilhos $/ \mathrm{m}^{2}$ para as doses de 75 e $300 \mathrm{~kg} / \mathrm{ha}$ de $\mathrm{N}$, respectivamente, com magnitude de resposta de 2,37 perfilhos mortos por $\mathrm{m}^{2} / \mathrm{kg}$ por ha de $\mathrm{N}$ aplicado. Uma possível explicação pode ser a baixa intensidade de pastejo antes do início das avaliações, levando à baixa incidência de luz no pasto, como relatado anteriormente. Resultados na literatura demonstram que o nitrogênio parece atuar de forma indireta na morte de perfilhos na pastagem (Auda et al., 1966), uma vez que estimula o turnover de tecidos, aumentando tanto o aparecimento quanto a mortalidade não só de perfilhos, além das folhas.

A porcentagem de lâminas foliares no capim-braquiária em março foi superior à observada nos meses de fevereiro e abril no primeiro ano (Tabela 4), possivelmente em decorrência das condições climáticas satisfatórias (Tabela 1). Assim, em razão da pouca variação na altura do pasto nesses meses, considera-se que a intensidade de pastejo não contribuiu efetivamente para essas variações.

No segundo ano (Tabela 4), as maiores porcentagens de lâminas ocorreram nos meses de dezembro a fevereiro. Assim, menores intensidades de pastejo impostas em dezembro e janeiro permitiram que maior porcentagem de lâminas fosse mantida no pasto. Mas, por outro lado, principalmente no mês de março, altas intensidades de pastejo resultantes da menor altura do pasto $(18 \mathrm{~cm})$ possivelmente provocaram consumo excessivo de lâminas foliares pelos novilhos na pastagem, uma vez que o componente folha é preferido pelos animais em pastejo.

A porcentagem de colmo do capim-braquiária (Tabela 4) no primeiro ano não teve influência dos meses de avaliação. Entretanto, no segundo ano, as porcentagens de colmo foram maiores em janeiro e fevereiro e menores em março e abril. Nesse caso, a intensidade de pastejo pode ter influenciado diretamente os resultados, pois a altura do pasto afeta diretamente a porcentagem de colmo na pastagem.

A relação lâmina:colmo foi maior nos meses em que foi observado maior incremento na proporção de lâminas. Assim, no primeiro ano, a relação lâmina:colmo no mês de março foi superior às dos meses de fevereiro e abril, em 
Tabela 4 - Porcentagens média de matéria seca de lâmina foliar, colmo, material morto (MM) e relação lâmina foliar:colmo (RLC) em pastagem de Brachiaria decumbens adubada com nitrogênio, durante os meses de avaliação, no primeiro e segundo ano

\begin{tabular}{|c|c|c|c|c|c|}
\hline Característica & Dezembro & Janeiro & Fevereiro & Março & Abril \\
\hline \multicolumn{6}{|c|}{ Primeiro ano } \\
\hline Lâmina foliar (\%) & - & - & $17 \mathrm{~b}$ & $30 \mathrm{a}$ & $20 \mathrm{~b}$ \\
\hline Colmo (\%) & - & - & $46 a$ & $44 \mathrm{a}$ & $48 \mathrm{a}$ \\
\hline Material morto (\%) & - & - & $37 a$ & $26 b$ & $32 \mathrm{ab}$ \\
\hline Relação lâmina:colmo & - & - & $0,37 b$ & $0,68 a$ & $0,42 b$ \\
\hline \multicolumn{6}{|c|}{ Segundo ano } \\
\hline Lâmina foliar (\%) & $24 \mathrm{a}$ & $23 a$ & $22 \mathrm{ab}$ & $15 c$ & $18 \mathrm{bc}$ \\
\hline Colmo (\%) & $39 b$ & $44 \mathrm{a}$ & $43 a b$ & $34 \mathrm{c}$ & $34 c$ \\
\hline Material morto (\%) & $37 b$ & $33 b$ & $35 b$ & $51 \mathrm{a}$ & $48 \mathrm{a}$ \\
\hline Relação lâmina:colmo & $0,62 \mathrm{a}$ & $0,52 \mathrm{ab}$ & $0,51 \mathrm{ab}$ & $0,44 \mathrm{~b}$ & $0,53 \mathrm{ab}$ \\
\hline
\end{tabular}

Médias na mesma linha seguidas da mesma letra não diferem (Tukey 5\%) entre si.

virtude da maior produção de lâminas nesse mês. No segundo ano, no entanto, só não houve incremento na relação lâmina:colmo no mês de março. Assim, independentemente do mês do ano, a relação lâmina:colmo pode ser considerada baixa, o que era esperado, em razão do manejo do pastejo adotado, ou seja, lotação contínua e altura do pasto mantida em $20 \mathrm{~cm}$, o que provavelmente influenciou a seletividade de pastejo pelos animais, que têm preferência por lâminas foliares.

Para a porcentagem de material morto (folhas e colmos mortos) na pastagem (Tabela 4), no primeiro ano, maiores valores foram constatados nos meses de fevereiro e abril. Uma possível explicação pode ser o acúmulo desse componente na pastagem antes do início das avaliações (janeiro), conforme já discutido anteriormente. No segundo ano, altas porcentagens de material morto foram observadas nos meses de março e abril em relação aos demais meses avaliados (Tabela 4), possivelmente em decorrência do aumento expressivo nas populações de perfilhos mortos $/ \mathrm{m}^{2}$ nesses meses (Tabela 3) e das condições climáticas, uma vez que no período chuvoso o turnover de tecidos é acentuado e tanto a sobrevivência quanto a mortalidade de perfilhos são aceleradas. Entretanto, no fim do período chuvoso, a maior tendência de acúmulo de material morto é maior, já que a capacidade de renovação de folhas e perfilhos passa a ser limitada pela condição ambiental, não somente chuva, mas também radiação.

Não houve influência das doses de nitrogênio nas proporções de lâminas foliares, cujas médias foram de 22 e $20 \%$, respectivamente, para o primeiro e segundo ano. Esses resultados podem ser explicados pelo sistema de pastejo, com lotação contínua e taxa variável, ou seja, possíveis aumentos nas proporções de lâminas, decorrentes da maior disponibilidade de nitrogênio, que podem ter sido neutralizados pelo aumento na taxa de lotação animal (Nabinger, 1997), uma vez que o propósito foi manter a mesma intensidade de pastejo em todas as doses de nitrogênio (altura de $20 \mathrm{~cm}$ ).

As doses de nitrogênio também não influenciaram as porcentagens de colmo e material morto no primeiro ano, cujas médias de $46 \%$ e $32 \%$, respectivamente. No segundo ano, ocorreu influência do nitrogênio nessas características $\left(\hat{\mathrm{y}}=28,849+0,0542 * \mathrm{~N} ; \mathrm{R}^{2}=0,92\right)$ e $\hat{\mathrm{y}}=55,287-0,0765547 * \mathrm{~N} ; \mathrm{R}^{2}=0,93$, respectivamente). Por outro lado, não houve resposta da relação lâmina:colmo ao nitrogênio aplicado, com médias de 0,49 e 0,51 para o primeiro e segundo ano, respectivamente.

Os valores de IAF no primeiro ano, nos meses de março e abril foram significativamente superiores ao valor observado em fevereiro (Tabela 5). Nesse último mês, o nitrogênio aplicado pode ter sido, em parte, perdido por lixiviação, em decorrência das condições climáticas (Tabela 1). No segundo ano (Tabela 5), verificaram-se maiores valores de IAF nos meses de fevereiro e março. Os mais altos valores de IAF coincidiram com as datas de parcelamento das adubações nitrogenadas (fevereiro e março), portanto, essa pode ser uma possível causa para esses aumentos. Além disso, a possibilidade de maiores valores de IAF para alturas do pasto similares (Tabela 2) é reconhecida em situações em que as plantas se encontram em fase de desenvolvimento reprodutivo (Robson et al., 1988), fato característico nos meses de fevereiro e março. O nitrogênio aplicado também acelera o surgimento de perfilhos reprodutivos na pastagem, via alocação de carbono nos meristemas (Nabinger, 1997), apresentando efeito mais expressivo nos meses em que normalmente o capim-braquiária floresce (fevereiro e março).

O índice de área foliar aumentou linearmente com a adubação nitrogenada, cujos valores foram de 2,74 e 4,28 e de 2,76 e 4,39 para as doses de 75 e $300 \mathrm{~kg} / \mathrm{ha}$ de $\mathrm{N}$ no 
primeiro $\left(\hat{\mathrm{y}}=2,23+0,00685^{* *} \mathrm{~N} ; \mathrm{R}^{2}=0,88\right)$ e segundo ano $\left(\hat{y}=2,21+0,00728 * N ; R^{2}=0,99\right)$, respectivamente.

A taxa de acúmulo de matéria seca de forragem (TAcMS) foi influenciada pelos meses de avaliação nos dois anos (Tabela 5). No primeiro ano, as TAcMS nos meses de fevereiro e março não diferiram entre si, entretanto, foram superiores à do mês de abril. O mesmo comportamento foi observado no segundo ano, quando as TAcMS nos meses de dezembro a março não diferiram entre si, mas foram superiores $(\mathrm{P} \leq 0,05)$ à do mês de abril. Efeito diferencial dos demais meses do ano em relação ao mês de abril para a TAcMS reflete a ação dos fatores de ambiente (Tabela 1) e do manejo do pastejo (Tabela 2) que alteraram as TAcMS da forragem na pastagem.

De fato, abril foi o mês em que houve menor incremento no IAF do pasto (Tabela 5) e mais alta população de perfilhos mortos $/ \mathrm{m}^{2}$ (Tabela 3), provavelmente em decorrência do déficit hídrico acentuado (Tabela 1), tanto no primeiro quanto no segundo ano. Como pode ser observado no mês de fevereiro do primeiro ano, houve baixo aumento no IAF, como consequência do excesso de chuvas, mas a demografia de perfilhos vivos $/ \mathrm{m}^{2}$ foi a mais elevada e a população de perfilhos mortos foi a mais baixa em comparação aos outros meses. Da mesma forma, no segundo ano, em dezembro o IAF atingiu valor tão baixo quanto no mês de abril, mas não houve morte acentuada de perfilhos $/ \mathrm{m}^{2}$. Ao contrário, em março houve elevada morte de perfilhos $/ \mathrm{m}^{2}$, mas o IAF atingiu valor mais elevado. Esses resultados estão em concordância com o observado por Lupinacci (2002) em pastagens de Brachiaria brizantha cv. Marandu em diferentes alturas e meses de avaliação sob pastejo em lotação contínua.

$\mathrm{Na}$ avaliação do efeito das doses de nitrogênio na TAcMS, observou-se ajuste dos dados às equações de regressão linear positiva $(\mathrm{P} \leq 0,10)$, tanto para o primeiro $\left(\hat{y}=29,92+0,29^{*} N ; R^{2}=0,99\right)$ quanto para o segundo ano $\left(\hat{y}=109,85+0,14427^{*} N ; R^{2}=0,98\right)$. Como era esperado, pastos mantidos em mesma intensidade de pastejo e com maior disponibilidade de nitrogênio apresentam maiores TAcMS.

Observou-se interação significativa entre as doses de nitrogênio e os meses de avaliação apenas para algumas características de composição química da forragem. Entretanto, optou-se pelo desdobramento da interação para todas as características.

Para os teores de proteína bruta (PB) constatou-se efeito dos meses de avaliação $(P \leq 0,05)$ e das doses de nitrogênio aplicadas ( $\mathrm{P} \leq 0,01, \mathrm{P} \leq 0,05$ e $\mathrm{P} \leq 0,10)$ (Tabela 7). No primeiro ano, a média no mês de fevereiro foi superior à do mês de abril e semelhante à média do mês de março em todas as doses de nitrogênio. Essa superioridade em relação às de abril sofreu influência, possivelmente, das melhores condições de ambiente, principalmente precipitação (Tabela 1), o que pode ter contribuído para maiores disponibilidades de nitrogênio, aumentando sua absorção e concentração na parte aérea das plantas.

No segundo ano, em geral, houve pouca consistência do efeito dos meses de avaliação nos teores de PB da gramínea com as doses de nitrogênio, o que resultou em diferenças pouco expressivas (Tabela 6). Entretanto, na dose de $150 \mathrm{~kg} / \mathrm{ha}$, a média no mês de fevereiro foi estatisticamente superior às de dezembro, março e abril, mas não diferiu daquela no mês de janeiro. Também, de forma geral, as médias em fevereiro e abril, nas doses de 225 e $300 \mathrm{~kg} / \mathrm{ha}$, foram superiores àquela observada no mês de dezembro. Entretanto, não diferiram daquelas dos meses de janeiro e março. Para a dose de 75 kg/ha, não foi constatada influência dos meses de avaliação nos teores de PB. A superioridade dos teores de PB, na maioria dos casos em fevereiro (Tabela 6), pode ser explicada pelo maior IAF registrado nesse mês (Tabela 5), assim como pela não-limitação dos fatores ambientais (Tabela 1), que como já discutido, tem efeito benéfico na absorção de nitrogênio pela forrageira.

Com relação aos efeitos do nitrogênio no teor de PB no capim-braquiária, houve resposta linear positiva $(\mathrm{P}<0,01$,

Tabela 5 - Índice de área foliar e taxa de acúmulo médios em pastagem de Brachiaria decumbens adubada com nitrogênio e avaliada em dois anos consecutivos

\begin{tabular}{|c|c|c|c|c|c|}
\hline Característica & Dezembro & Janeiro & Fevereiro & Março & Abril \\
\hline \multicolumn{6}{|c|}{ Primeiro ano } \\
\hline Índice de área foliar & - & - & $2,96 b$ & $3,94 a$ & $3,63 a$ \\
\hline Taxa de acúmulo de MS & - & - & $86,1 \mathrm{a}$ & $92,4 a$ & $74,4 \mathrm{~b}$ \\
\hline \multicolumn{6}{|c|}{ Segundo ano } \\
\hline Índice de área foliar & $2,69 c$ & $3,71 b$ & $4,73 a$ & 4,19ab & $2,55 c$ \\
\hline Taxa de acúmulo de MS & $137,7 a$ & $133,0 \mathrm{a}$ & $149,7 a$ & $143,0 \mathrm{a}$ & $121,0 \mathrm{~b}$ \\
\hline
\end{tabular}

Médias na mesma linha seguidas da mesma letra não diferem $(\mathrm{P}>0,05)$ entre si pelo teste Tukey. 
Tabela 6 - Teores médios de proteína bruta na matéria seca total em pastagem de Brachiaria decumbens adubada com nitrogênio e avaliada em dois anos consecutivos

\begin{tabular}{|c|c|c|c|c|c|c|}
\hline Meses & \multicolumn{4}{|c|}{ Doses de nitrogênio (kg/ha) } & Equação & $\mathrm{R}^{2}$ \\
\hline & \multicolumn{6}{|c|}{ Primeiro ano } \\
\hline •Março & $6,77 b$ & 7,83ab & $8,87 \mathrm{ab}$ & $9,2 \mathrm{ab}$ & $\hat{y}=6,09+0,0111^{+} N$ & 0,96 \\
\hline •Abril & $5,08 b$ & $6,52 b$ & $7,91 b$ & $8,19 b$ & $\hat{y}=4,25+0,0143 * N$ & 0,94 \\
\hline Janeiro & $5,87 a$ & $8,32 \mathrm{ab}$ & $8,30 \mathrm{ab}$ & $8,76 a b$ & $\hat{\mathrm{y}}=5,65+0,0115^{* *} \mathrm{~N}$ & 0,72 \\
\hline •Fevereiro & $6,07 \mathrm{a}$ & $9,02 \mathrm{a}$ & $9,14 \mathrm{a}$ & $9,61 \mathrm{a}$ & $\hat{\mathrm{y}}=5,78+0,0143^{* *} \mathrm{~N}$ & 0,74 \\
\hline •Março & $4,88 \mathrm{a}$ & $6,05 c$ & 7,39ab & $7,97 \mathrm{ab}$ & $\hat{y}=4,27+0,0114 * * N$ & 0,87 \\
\hline Abril & $6,42 \mathrm{a}$ & $7,17 \mathrm{bc}$ & $8,88 a$ & $9,94 a$ & $\hat{y}=5,04+0,01636^{* *} N$ & 0,98 \\
\hline
\end{tabular}

Médias na mesma coluna para cada ano, seguidas da mesma letra, não diferem $(P>0,05)$ entre si pelo teste Tukey.

**, *, ${ }^{+}$: Significativo a 1,5 e $10 \%$ de probabilidade pelo teste $\mathrm{F}$.

- Adubação nitrogenada prévia (1/3 da dose).

$\mathrm{P}<0,05$ e $\mathrm{P}<0,10$ ) em todos os meses de avaliação (Tabela 6), tendo nos dois anos, a magnitude de resposta do capimbraquiária variou entre 0,007 e 0,016 unidade percentual de PB/kg de N aplicado. Segundo Gomide (1989), não se deve esperar alteração substancial na composição química da forragem pela adubação nitrogenada, em virtude do efeito mais pronunciado na produção de forragem em comparação aos efeitos nos teores de proteína bruta.

Os teores de fibra em detergente neutro (FDN) foram influenciados $(\mathrm{P}<0,05)$ pelos meses de avaliação, porém não foram alterados $(\mathrm{P}>0,10)$ pela adubação nitrogenada (Tabela 7). No primeiro ano, os teores de FDN em abril foram superiores $(\mathrm{P}<0,05)$ às médias nos meses de fevereiro e março, e às médias no mês de março, apenas nas doses de 75 e de $150 \mathrm{~kg} / \mathrm{ha}$ de $\mathrm{N}$, respectivamente. Nas outras doses, não houve influência $(\mathrm{P}>0,05)$ dos meses nos teores de FDN da forrageira. Também no segundo ano, em geral no mês de abril, as médias foram superiores $(\mathrm{P}<0,05)$ às dos demais meses nas doses de 150 a $300 \mathrm{~kg} / \mathrm{ha}$, de modo que, para a dose de $75 \mathrm{~kg} / \mathrm{ha}$, apenas o mês de dezembro foi inferior $(\mathrm{P}<0,05)$ à média referente ao mês de abril. Essa superioridade em abril pode ser explicada possivelmente pela limitação de fatores de ambiente, principalmente precipitação pluvial, que pode ter contribuído para maiores deposições de constituintes de parede celular na forrageira em detrimento do conteúdo celular, alterando seus teores (Tabela 1), o que, em última análise (Van Soest, 1994), pode ter levado a maior limitação de consumo pelos animais.

Com relação aos efeitos do nitrogênio nos teores de FDN do capim-braquiária (Tabela 7), não foram constatadas diferenças $(P>0,10)$ em nenhum mês de avaliação, registrando-se médias de $76,2 \%$.
No primeiro ano (Tabela 8), os meses de avaliação influenciaram $(\mathrm{P}<0,05)$ os teores de lignina. Entretanto, no segundo ano, essas diferenças não foram observadas. Esses resultados inconsistentes também corroboram aqueles de Paciullo et al. (2001), os quais da mesma forma, não encontraram influência da estação de crescimento nos teores de lignina da parte aérea de gramíneas tropicais. Também não houve efeito $(\mathrm{P}>0,10)$ das doses de nitrogênio no teor de lignina, cujo valor médio foi de 11,3\% (Tabela 8).

Os coeficientes de digestibilidade in vitro da matéria seca total (DIVMST) foram influenciados $(\mathrm{P}<0,05)$ pelos meses de avaliação (Tabela 9) e pelo ano, pois o valor no mês de fevereiro foi superior $(\mathrm{P}<0,05)$ ao do mês de abril, nas doses avaliadas. No segundo ano, o mês de dezembro foi o único que apresentou DIVMST superior $(\mathrm{P}<0,05)$ à média mais baixa obtida em abril. Os menores coeficientes de DIVMST podem ser atribuídos às limitações de fatores de ambiente, sobretudo a precipitação (Tabela 1) de abril. Assim, os altos teores de FDN na planta influenciaram no declínio dos seus coeficientes de DIVMST, uma vez que a alta correlação negativa $(\mathrm{P}<0,05)$ foi registrada $(-0,79)$ para os dois componentes.

As doses de nitrogênio (Tabela 9) tiveram efeito significativo no coeficiente de DIVMST apenas em março do primeiro ano. Assim, nos demais meses dos dois anos, a adubação nitrogenada não alterou $(\mathrm{P}>0,10)$ a digestibilidade do capim-braquiária, cuja média geral foi de $54,6 \%$. Esse baixo valor médio para o coeficiente de DIVMST também pode ser atribuído ao manejo do pastejo adotado, ou seja, a lotação contínua e a altura do pasto mantida em $20 \mathrm{~cm}$ podem ter tido influência no maior consumo de lâminas foliares, em decorrência da preferência dos animais por essa 
Tabela 7 - Teores médios de fibra em detergente neutro (\%) na matéria seca total em pastagem de Brachiaria decumbens adubada com nitrogênio e avaliada em dois anos consecutivos

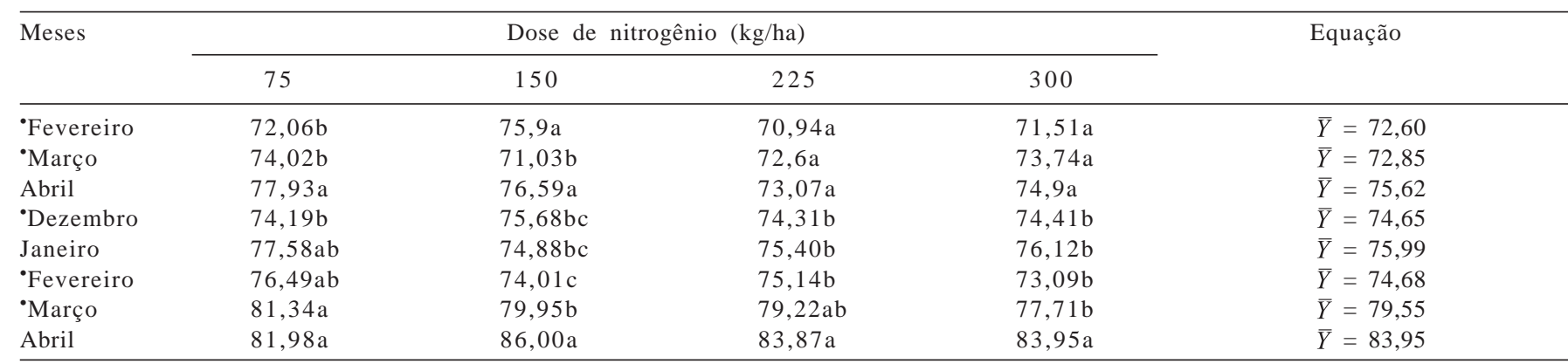

Médias na mesma coluna para cada ano, seguidas da mesma letra, não diferem $(\mathrm{P}>0,05)$ entre si pelo teste Tukey.

- Adubação nitrogenada prévia (1/3 da dose).

Tabela 8 - Teores médios de lignina na matéria seca total em pastagem de Brachiaria decumbens adubada com nitrogênio e avaliada em dois anos consecutivos



Médias na mesma coluna para cada ano, seguidas da mesma letra, não diferem $(\mathrm{P}>0,05)$ entre si pelo teste Tukey.

- Adubação nitrogenada prévia (1/3 da dose).

Tabela 9 - Digestibilidade in vitro da matéria seca total (DIVMST) média em pastagem de Brachiaria decumbens adubada com nitrogênio e avaliada em dois anos consecutivos

\begin{tabular}{|c|c|c|c|c|c|c|}
\hline Meses & \multicolumn{4}{|c|}{ Doses de nitrogênio $(\mathrm{kg} / \mathrm{ha})$} & Equação & $\mathrm{R}^{2}$ \\
\hline & & & & & Primeiro ano & \\
\hline •Fevereiro & $66,39 a$ & $71,61 \mathrm{a}$ & $69,48 a$ & $69,81 \mathrm{a}$ & $\hat{y}=69,32$ & - \\
\hline •Março & $59,82 \mathrm{ab}$ & $68,71 \mathrm{a}$ & $63,21 \mathrm{ab}$ & $56,23 b$ & $\hat{y}=46,23+0,2426 * * N-0,0007 * * N^{2}$ & 0,90 \\
\hline •Abril & $54,22 b$ & $54,17 b$ & $60,58 b$ & $54,86 b$ & $\hat{y}=55,96$ & - \\
\hline •Dezembro & $59,42 \mathrm{a}$ & $56,05 a$ & $55,71 \mathrm{a}$ & $58,62 \mathrm{a}$ & $\hat{y}=57,45$ & - \\
\hline Janeiro & $52,13 a b$ & $49,40 a b$ & $50,53 a b$ & $54,61 \mathrm{ab}$ & $\hat{y}=51,67$ & - \\
\hline •Fevereiro & $48,63 b$ & $54,43 a$ & $52,73 a b$ & $54,49 a b$ & $\hat{y}=52,57$ & - \\
\hline •Março & $45,52 b$ & $47,82 \mathrm{ab}$ & $49,28 \mathrm{ab}$ & $48,42 b$ & $\hat{\mathrm{y}}=47,76$ & - \\
\hline Abril & $48,18 b$ & $45,12 b$ & $45,27 b$ & $50,84 a b$ & $\hat{y}=47,35$ & - \\
\hline
\end{tabular}

Médias na mesma coluna para cada ano, seguidas da mesma letra, não diferem $(\mathrm{P}>0,05)$ entre si pelo teste Tukey.

** Significativo a $1 \%$ de probabilidade, pelo teste t.

- Adubação nitrogenada prévia (1/3 da dose).

fração da planta, de modo que a forragem residual disponível na pastagem pode ter tido sua DIVMST comprometida. Relatos na literatura sugerem que a adubação nitrogenada exerce pouca influência na DIVMST de gramíneas forrageiras tropicais, quando essas gramíneas estão em mesmo estádio de crescimento (Van Soest, 1994). 


\section{Conclusões}

A demografia de perfilhos em pastos de Brachiaria decumbens é influenciada pela época do ano e pelas condições ambientais. Além disso, o nitrogênio aumenta tanto o aparecimento quanto a mortalidade perfilhos. Em pastos de Brachiaria decumbens, o manejo em lotação contínua com altura do pasto de $20 \mathrm{~cm}$ influencia a seletividade de pastejo pelos animais, o que tem efeito direto na relação lâmina:colmo. A taxa de acúmulo de forragem em pastos de capim-braquiaria é menor em épocas do ano com condições ambientais (temperatura, precipitação, insolação) desfavoráveis e aumenta com a adubação nitrogenada. A qualidade da forragem em capim-braquiária é mais influenciada pela estação do ano (verão e inverno) que pela adubação nitrogenada.

\section{Literatura Citada}

AUDA, H.; BLASER, R.E.; BROWN, R.H. Tillering and carbohydrate contents of orchardgrass as influenced by environmental factors. Crop Science, v.6, n.2, p.139-143, 1966.

CAMPBELL, A.G. Grazed pasture parameters. I. Pasture dry-matter production and availability in a stocking rate and grazing management experiment with dairy cows. Journal of Agricultural Science, v.67, p.199-210, 1966a.

CAMPBELL, A.G. Grazed pasture parameters. II. Pasture dry matter use in a stocking rate and grazing management experiment with dairy cows. Journal of Agricultural Science, v.67, p.211-216, 1966b.

CAVALCANTE, M.A.B. Características morfogênicas, estruturais e acúmulo de forragem em relvado de Brachiaria decumbens cv. Basilisk sob pastejo, em diferentes alturas. 2001. 64f. Dissertação (Mestrado em Zootecnia) - Universidade Federal de Viçosa, Viçosa, MG, 2001.

GOMIDE, J.A. Aspectos biológicos e econômicos da adubação de pastagens. In: SIMPÓSIO SOBRE ECOSSISTEMAS DE PASTAGENS, 1., 1989, Jaboticabal. Anais... Jaboticabal: FUMEP, 1989. p.237-270.

GOMIDE, J.A.; GOMIDE, C.A.M.; GRASSELLI, L.C.P. et al. Acúmulo e consumo de forragem em relvado de B. decumbens mantido a diferentes alturas sob pastejo de lotação contínua variável. In: REUNIÃO ANUAL DA SOCIEDADE BRASILEIRA DE ZOOTECNIA, 39., 2002, Recife. Anais... Recife: Sociedade Brasileira de Zootecnia, 2002. (CD-ROM).

KLINGMAN, D.L.; MILES, S.R.; MOTT, G.O. The cage method for determining consumption and yield of pasture herbage. Journal of the American Society of Agronomy, v.35, n.9, p.739-747, 1943.
KÖPPEN, W. Climatologia. Buenos Aires: Gráfica Panamericana, 1948. 478p.

LUPINACCI, A.V. Reservas orgânicas, índice de área foliar e produção de forragem em Brachiaria brizantha cv. Marandu submetida a intensidades de pastejo por bovinos de corte. 2002. 160f. Dissertação (Mestrado em Agronomia) - Escola Superior de Agricultura "Luiz de Queiroz”, Piracicaba, 2002.

MACEDO, M.C.M. Análise comparativa de recomendações de adubação em pastagens. In: SIMPÓSIO SOBRE MANEJO DA PAstagem, 21., 2004, Piracicaba. Anais... Piracicaba: Fundação de Estudos Agrários Luiz de Queiroz, 2004. p.317-356.

MATTHEW, C.; LEMAIRE, G.; SACKVILLE HAMILTON, N.R. et al. A modified self-thinning equation do describe size/density relationships for defoliated swards. Annals of Botany, v.76, p.579-587, 1995.

MORAIS, R.V.; FONSECA, D.M.; NASCIMENTO JR., D. et al. Demografia de perfilhos basilares em pastagem de Brachiaria decumbens adubada com nitrogênio. Revista Brasileira de Zootecnia, v.35, n.2, p.380-388, 2006.

MOREIRA, L.M.; FONSECA; D.M.; FAGUNDES, J.L. et al. Renovação de pastagem de capim-gordura na Zona da Mata Mineira com a introdução de gramíneas, leguminosa e adubação nitrogenada. Composição químico-bromatológica. In: REUNIÃO ANUAL DA SOCIEDADE BRASILEIRA DE ZOOTECNIA, 40., 2003, Santa Maria. Anais... Santa Maria: Sociedade Brasileira de Zootecnia, 2003. (CD-ROM).

NABINGER, C. Eficiência do uso de pastagens: disponibilidade e perdas de forragem. In: SIMPÓSIO SOBRE MANEJO DA PASTAGEM, 14., 1997, Piracicaba. Anais... Piracicaba: Fundação de Estudos Agrários Luiz de Queiroz, 1997. p.213-252.

PACIULLO, D.S.C.; GOMIDE, J.A.; QUEIROZ, D.S. et al. Composição química e digestibilidade "in vitro" de lâminas foliares e colmos de gramíneas forrageiras, em função do nível de inserção no perfilho, da idade e da estação de crescimento. Revista Brasileira de Zootecnia, v.30, n.3, p.964-974, 2001.

ROBSON, M.J.; RYLE, G.J.A.; WOLEDGE, J. The grass plant its form and function. In: JONES, M.B.; LAZENBY, A. (Eds.) The Grass crop: the physiological basis of production. London: Chapman \& Hall, 1988. p.25-83.

SBRISSIA, A.F.; DA SILVA, S.C.; CARVALHO, C.A.B. et al. Tiller size/population density compensation in Coastcross grazed swards. Scientia Agricola, v.58, n.4, p.655-665, 2001.

SILVA, D.J.; QUEIROZ, A.C. Análise de alimentos (métodos químicos e biológicos). 3.ed. Viçosa, MG: Universidade Federal de Viçosa, 2002. 235p.

TILLEY, J.M.A.; TERRY, R.A. A two-stage technique for the in vitro digestion of forage crops. Journal British Grassland Society, v.18, n.2, p.104-111, 1963.

Van SOEST, P.J. Voluntary intake relation to chemical composition and digestibility. Journal Animal Science, v.24, n.3, p.834-844, 1965.

Van SOEST, P.J. Nutritional ecology of the ruminant. 2.ed., Cornell University Press, 1994. 476p.

WERNER, J.C. Adubação de pastagens de Brachiaria spp. In: SIMPÓSIO SOBRE MANEJO DA PASTAGEM, 11., 1994, Piracicaba. Anais... Piracicaba: Fundação de Estudos Agrários Luiz de Queiroz, 1994. p.209-222. 